\title{
CHARACTERIZATION OF SOME CLAYS USED FOR WHITEWARE CERAMICS II. TECHNOLOGICAL CHARACTERIZATION
}

\author{
MARIA GOREA, MARCEL BENEA ${ }^{1}$
}

\begin{abstract}
The paper investigates the mineral composition of four diferent clay types used for whiteware ceramics, correlated to the measured mineralogical and chemical composition, particle size distribution and technological characteristics (plasticity, drying, and firing shrinkage, dry resistance). According to their particle size distribution, the U-II, U-III and ESV3 clay types are almost identically, but the mineralogical composition is different. On the other hand, the CARO clay type has a very similar kaolinite and quartz content with U-II clay, but shows a completely different particle size distribution. Based on the mineralogical and particle size distribution, CARO clay type shows the most suitable technological properties.
\end{abstract}

Key words: clays, clay minerals, whiteware, ceramics

\section{INTRODUCTION}

Ceramic products are obtained as a result of a specific procedure of processing of clayey raw materials, feldspars and sand. During wet preparation and forming stages, it is important that ceramic slurries and pastes show a good rheology, plasticity, and binding capacity for nonclay raw materials; all these properties influence the shrinkage, and thus the mechanical resistance of the products. These features depend on the nature, ratio and size of clay particles as compared to the nonclay materials.

Conventional ceramics are obtained from clay minerals, feldspars, and quartz. Clay minerals are provided by kaolines and other clays, and represent more than $50 \%$ of the ceramic mass. They ensure a good behaviour of ceramic slurries at wet preparation and forming (plasticity, rheology), and finally they influence the properties of the firing product (Hoffman, 1991).

The main mineral phases within clays are kaolinite, quartz, and micas. Carbonates and small amounts of feldspars, chlorites, montmorillonite, interstratified minerals, and compounds of $\mathrm{Ti}$ and $\mathrm{Fe}$ are considered to be impurities, some showing a strong negative effect on the final product.

In general, the technological process was hardly adaptated to mechanization and automatization of certain flow stages, due to the compositional heterogeneity of natural raw materials. Modern methods of investigation allow nowadays a rigurous control of raw materials and accordingly, the possibility of adaptation of certain ceramic masses compositions to the existing materials. Alternatively, specific ceramic compositions can be recommended for proper types of final products.

\footnotetext{
1 “Babeș-Bolyai” University, Department of Mineralogy, 1 Kogă Iniceanu St., RO-3400 Cluj Napoca
} 
Besides the economic arguments, in the last years the quality of raw materials was more and more considered, due to the effects on the technological behaviour, microstructure, and final properties of ceramic products (Reed, 1995).

In this respect, this second part of the paper intends to establish a correlation between mineralogical, chemical compositions and granulometry of four raw clays used for whiteware production (sanitary products) or experimental lots, vs. the technological behaviour during wet preparation (rheology, plasticity), forming (dry resistance), thermal treatment (drying and firing shrinkage).

\section{EXPERIMENTAL WORK}

The ceramic raw materials are natural or synthetic materials that provide, after processing, the main mineral phases requested for obtaining a corresponding microstructure of ceramics, and the features needed for a specific usage of the final products.

Two main raw material types are used for obtaining conventional ceramics:

- clays - they confer plasticity to the ceramic masses and thus the forming capacity (kaolines and other clays);

- nonclay materials - they reduce the shrinkage and prevent the fissuration upon thermal treatment, thus playing an important role in the formation of the final microstructure of ceramics (feldspar, sand).

The ratio of nonclay materials in the ceramic masses is established according to the characteristics of clays, first of all to their binding capacity for these materials.

\section{Mineralogical composition}

Mineralogical composition of the clays used for ceramics is very important to be known because it has a great influence on the technological behaviour and on the final properties of fired products.

In the first part of this paper (Benea \& Gorea, 2002) by using the X-ray diffraction analyses and scanning electron microscopy, the mineralogical composition was determined. The qualitative and semiquantitative data of the studied clay types (UIII and UII samples originate from Ukraine, CARO and ESV3 from Great Britain) are presented in Table 1.

Table 1

Mineralogical composition of the analysed clays (wt. \%)

\begin{tabular}{|l|r|r|c|c|}
\hline \multirow{2}{*}{ Mineral } & \multicolumn{4}{|c|}{ Clay type / sample number } \\
\cline { 2 - 5 } & UIII / 4806 & UII / 4807 & CARO / 4808 & ESV3 / 4809 \\
\hline Quartz & 11.40 & 25.70 & 25.50 & 15.50 \\
Kaolinite & 77.50 & 57.35 & 51.40 & 63.55 \\
Vermiculite & 2.50 & 12.20 & 2.00 & 20.95 \\
IIllite & 8.60 & 4.75 & 20.10 & 0.00 \\
„mixed layers“ & 0.00 & 0.00 & 1.00 & 0.00 \\
\hline
\end{tabular}




\section{CHARACTERIZATION OF SOME CLAYS USED FOR WHITEWARE CERAMICS}

\section{Chemical composition}

The chemical composition of clays varies within broad limits, being a "measure" of their general properties. This is due to the fact that the same oxide may be present in several mineral phases that show opposite influences on the ceramics (Teoreanu et al., 1985). For example, aluminium oxide in kaolinite leads to increased plasticity and refractarity, while in feldspars it acts as a plasticity reducing material in the process of wet preparation, or as fluxing agent at firing.

As a consequence, two clays with similar compositions may show a different technological behaviour, according to the particular mineral components.

The chemical composition of the studied clays (determined by X-ray fluorescence, XRF, at S.C. SANEX S.A. laboratory) is presented in Table 2.

According to the chemical contents it can be concluded that the samples show similar values, except for $\mathrm{U}$-II type that has a lower $\mathrm{Al}_{2} \mathrm{O}_{3}$ content and a higher $\mathrm{SiO}_{2}$ one, while $\mathrm{U}$-III type shows a reverse ratio among these oxides. These differences cannot explain the different technological behaviour.

Table 2

Chemical composition of the studied clays (wt. \%)

\begin{tabular}{|l|l|l|l|l|l|l|l|l|l|}
\hline $\begin{array}{l}\text { Oxide } \\
\text { Clay }\end{array}$ & $\mathrm{SiO}_{2}$ & $\mathrm{Al}_{2} \mathrm{O}_{3}$ & $\mathrm{TiO}_{2}$ & $\mathrm{Fe}_{2} \mathrm{O}_{3}$ & $\mathrm{CaO}$ & $\mathrm{MgO}$ & $\mathrm{Na}_{2} \mathrm{O}$ & $\mathrm{K}_{2} \mathrm{O}$ & L.O.I. \\
\hline $\mathrm{U}$-III & 48.13 & 33.82 & 2.00 & 1.06 & 0.65 & 0.50 & 0.00 & 0.35 & 13.48 \\
\hline $\mathrm{U}$-II & 59.43 & 26.39 & 1.77 & 0.98 & 0.45 & 0.35 & 0.00 & 0.40 & 10.22 \\
\hline CARO & 53.35 & 30.33 & 1.23 & 0.99 & 0.09 & 0.47 & 0.13 & 2.06 & 11.35 \\
\hline ESV 3 & 53.12 & 31.01 & 2.30 & 0.95 & 0.60 & 0.36 & 0.02 & 0.40 & 11.26 \\
\hline
\end{tabular}

\section{Particle size distribution}

The particle size distribution of raw materials influences their behaviour during the technological process and affects many properties of clay ceramic products.

Clay particles are characterized by a high surface energy determined by the presence of negative charges; meanwhile, inside the structure, the neutrality of the molecules is preserved. As a consequence, the properties of clays are highly influenced by the surface phenomena; the degree of dispersion determines the increase of the specific surface, thus of the surface energy.

The particle size distribution of the analysed samples obtained by using a laser granulometer of a FRITSCH-ANALYSETTE 22-type at S.C. FAIMAR S.A. Baia Mare is presented in Figs. 1, 2, 3, and 4.

The diagrams indicate a broad range of distribution, between 0.5 to 50 $\mu \mathrm{m}$, with two peaks in the case of U-III and U-II clay types, and a relatively flat curve in the case of ESV-3 clay type; alternatively, a narrow range of variation, 0.5 to $8 \mu \mathrm{m}$ and a single maximum are to be noticed in the case of CARO type. 


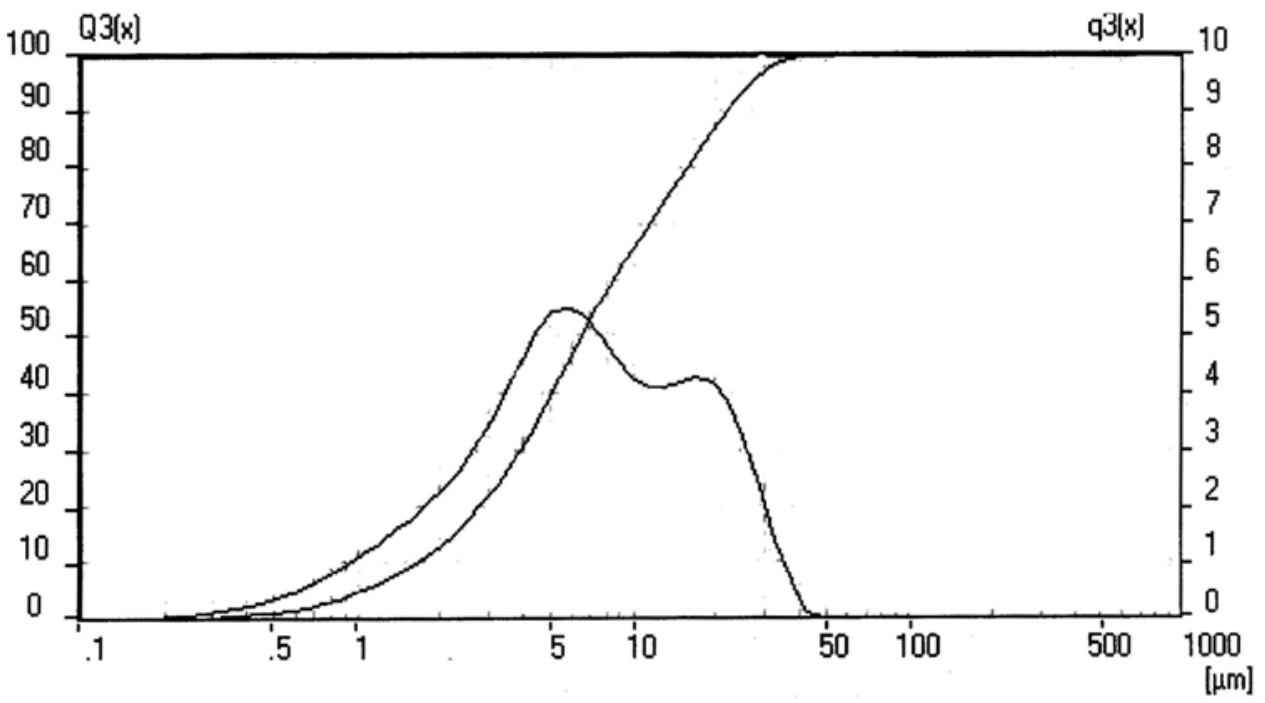

Figure 1. Grain-size distribution of U-III clay type

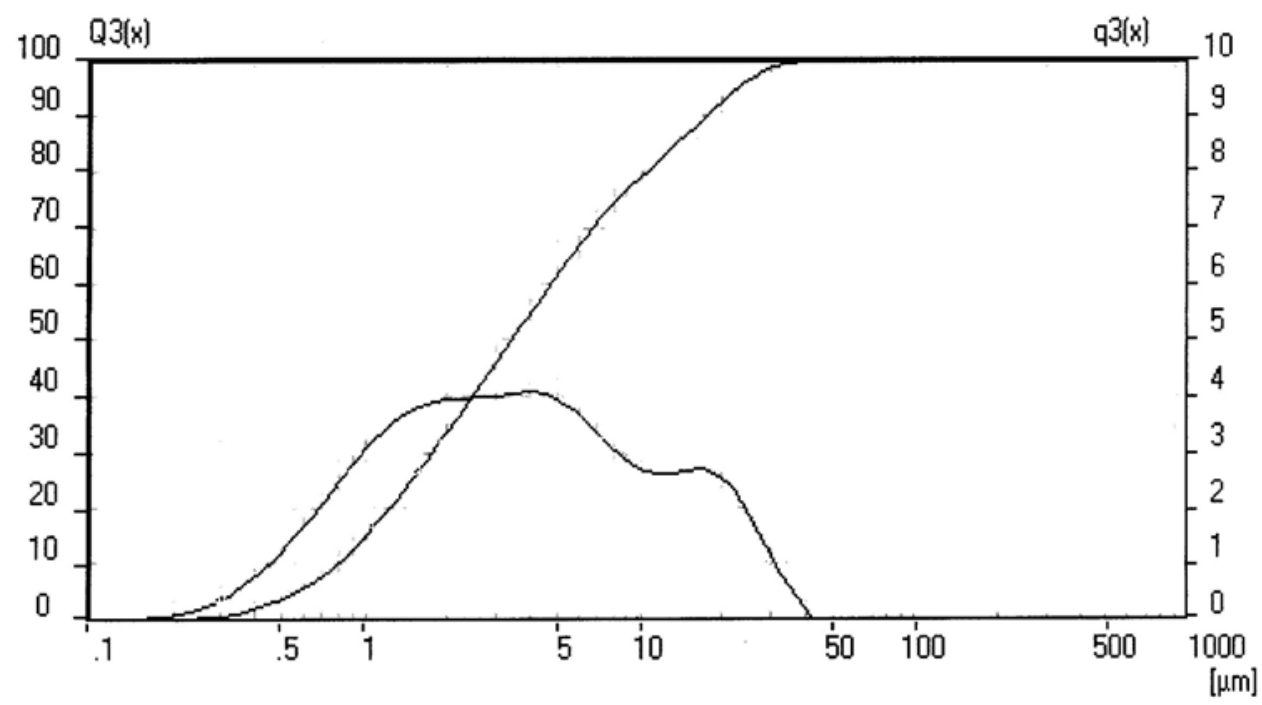

Figure 2. Grain-size distribution of U-II clay type 


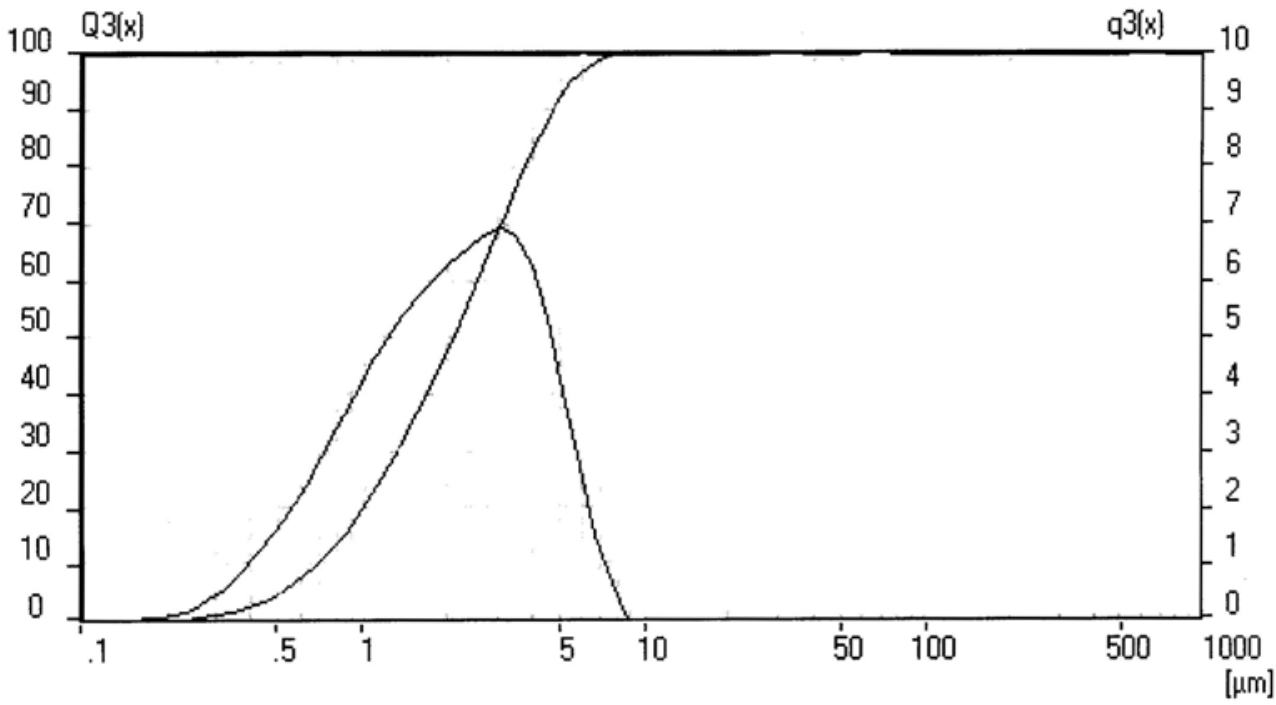

Figure 3. Grain-size distribution of CARO clay type

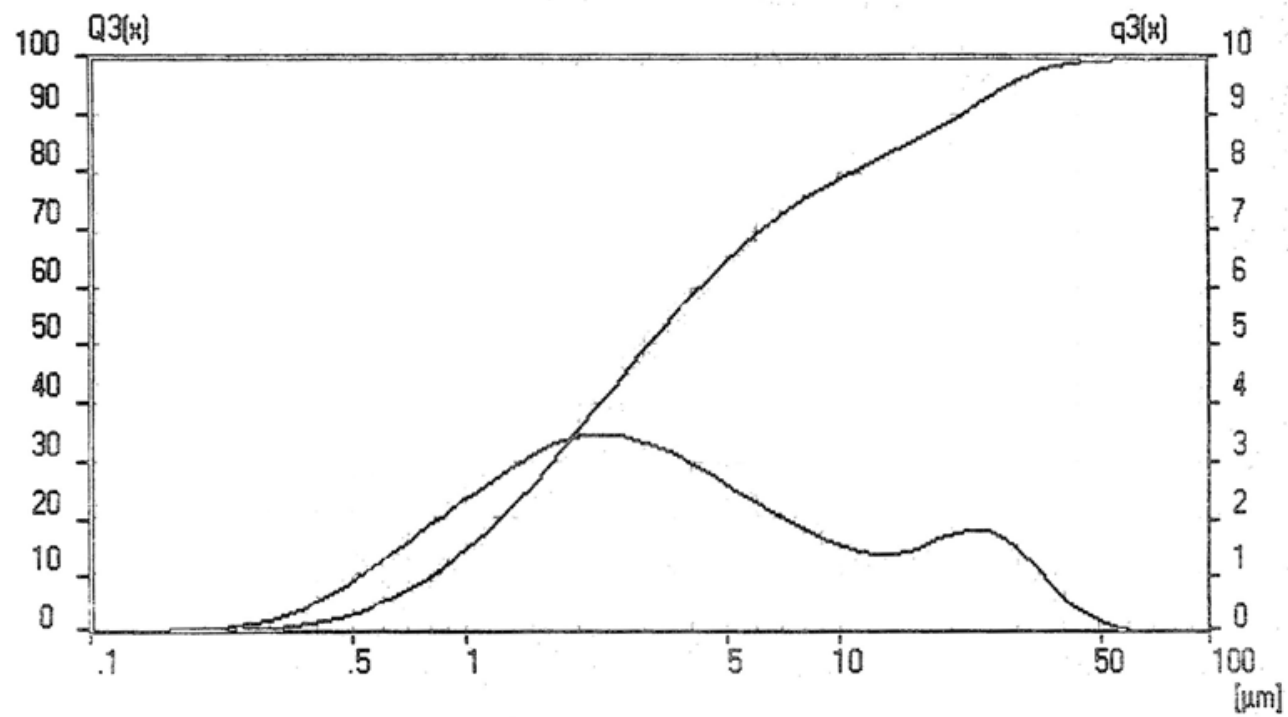

Figure 4. Grain-size distribution of ESV3 clay type 
According to their granulometry, the four samples belong to the following rock-types (Table 3):

Table 3

Classification of the samples according to the granulometry

\begin{tabular}{|c|c|c|c|}
\hline \multirow{2}{*}{ Sample } & \multicolumn{3}{|c|}{ Particle size [mm] } \\
\cline { 2 - 4 } & $<0.005$ & $0.005-0.060$ & Granulometric type \\
\hline UIII [\%] & 38.94 & 61.06 & Clayey silt \\
\hline UII [\%] & 61.53 & 38.47 & Siltic clay \\
\hline CARO [\%] & 92.18 & 7.82 & Clay \\
\hline ESV3 [\%] & 64.64 & 35.36 & Siltic clay \\
\hline
\end{tabular}

\section{Technological characteristics of the clays}

When mixed with water, the clay particles with negative surface charges behave as macroanions due to the presence of unbonded anions or to isomorphous substitutions in the aluminosilicate network. The water dipoles orient themselves with the positive pole (hydrogen) towards the particle surface, thus leading to the formation of several water layers. Their degree of ordering and intensity of the bonding decreases with the increase of the distance from the clay particle. The water adsorbtion gives birth to a fixed, and respectively to a mobile adsorbed layer that contribute to the binding and lubrication of the solid particles. The amount of adsorbed water depends on the presence of certain cations (from the clay or supplimentary added) and it influences the capacity of forming of ceramic masses by the means of rheology of slurries, plasticity of pastes, mechanical resistance, and drying shrinkage.

From this point of view, the factors that influence the forming of ceramic masses are represented by the mineralogical nature and size of the clay minerals, and the dispersion environment respectively.

In practice, when establishing the fields of usage of clays and their ratio in the ceramic mass composition, not only their chemical composition, but also their mineralogy, particle size distribution and their correlation with the technological characteristics are important.

The technological features of the studied clays are presented in Table 4.

Table 4

Technological characteristics of the studied clays

\begin{tabular}{|l|l|l|l|l|l|}
\hline $\begin{array}{c}\text { Characteristics } \\
\text { Clay type }\end{array}$ & \multicolumn{1}{|c|}{$\begin{array}{c}\text { Pfefferkorn } \\
\text { plasticity index [\%] }\end{array}$} & $\begin{array}{c}\text { Drying } \\
\text { shrinkage [\%] }\end{array}$ & $\begin{array}{c}\text { Firing } \\
\text { shrinkage [\%] }\end{array}$ & $\begin{array}{l}\text { Drying resistance } \\
{\left[\mathrm{kgf} / \mathrm{cm}^{2}\right]}\end{array}$ & Rheology \\
\hline U-III & 40.20 & 9.56 & 11.54 & 22.70 & weak \\
\hline U-II & 32.10 & 5.90 & 5.94 & 23.43 & none \\
\hline CARO & 38.60 & 5.10 & 7.51 & 23.26 & good \\
\hline ESV3 & 36.00 & 7.52 & 8.39 & 22.92 & medium \\
\hline
\end{tabular}

82 


\section{CHARACTERIZATION OF SOME CLAYS USED FOR WHITEWARE CERAMICS}

Plasticity, measured by using Pfefferkorn method, is high in the case of U-III clay, as a consequence of the high content of clay minerals $(88.60 \%)$ and the low amount of quartz (11.40\%). The high amount of adsorbed water may be explained by the presence of kaolinite with a reduced crystallinity ("rolled" kaolinite) that determines higher values of drying and firing shrinkage (the highest values among the four samples). The high values of shrinkage lead to the occurrence of hidden fissures and implicitly to the decrease of mechanical resistance. U-II and ESV3 clay types show a reduced plasticity. The shrinkage and mechanical resistance are correlated with the mineralogical composition: a relatively higher amount of quartz (15.5\%) in ESV3 as compared to U-III leads to the decrease of plasticity with about $4 \%$, while in sample U-II with $25.70 \%$ quartz, plasticity decreases with $8 \%$. Shrinkage values show a similar trend, while the mechanical resistance increases, due to the decrease of the probability of fissure formation.

CARO clay shows the most suitable technological features, such as good rheology, forming, and drying. This is due to the mineralogical composition and particle size distribution of the sample that is dominated by clay-sized particles (Table 3). The narrow particle size range $(0.2-10 \mu \mathrm{m})$ with a single maximum is a result of the presence of minute quartz particles, which even in relatively high amount $(25.50 \%)$ are homogeneously distributed in the clay. The presence of illite and traces of interstratified minerals could also explain the rheology of the ceramic slurries, as a consequence of their cation exchange capacity in the clay-water system.

\section{Conclusions}

Our investigations on the clays used as raw materials for whiteware ceramics prove the importance of mineralogical composition and particle size distribution on the technological characteristics of ceramic pastes and slurries.

According to their particle size distribution, the U-II, U-III and ESV3 clay types are almost identically, but the mineralogical composition is different. On the other hand, the CARO clay type has a very similar kaolinite and quartz content with U-II clay, but shows a completely different particle size distribution.

The presence of illite, mixed layers and fine-grained quartz leads to the increase of slurries rheology. Thus is favourably influencing the plasticity, forming capacity, drying and firing shrinkage, and implicitly the mechanical resistance (by reducind the risk of fissure formation).

Based on the mineralogical and particle size distribution, CARO clay type shows the most suitable technological properties.

In conclusion, the specific technological properties of clays depend first of all on their mineralogical composition, but also on other factors, such as the size and morphology of the constituent particles, the crystallinity degree of various minerals, the presence of organic impurities, and of soluble salts. 
MARIA GOREA, MARCEL BENEA

\section{REFERENCES}

Benea, M., Gorea, M. (2002), Characterization of some clays used for whiteware ceramics. I. Mineralogical composition, Studia Univ. "Babeș-Bolyai”, Geologia, XLVII, 1, Cluj Napoca

Hoffmann, J. (1991), Tehnologia ceramicii fine, "Industria ușoară și alimentară ", Moscova, p. $10-13$

Reed, S. J. (1995), Principles of Ceramics Processing, “John Wiley \& Sons, Inc.”, New York, p. 33-118

Teoreanu, I., Ciocea, N., Bă rbulescu, A., Ciontea, N. (1985), Tehnologia produselor ceramice și refractare, Editura Tehnică , București, p.78-81 